\title{
Upgrading Air Distribution System in the Thermal Units for Fish and Meat Products Aiming at Improving Efficiency of Heat-exchange Processes
}

\author{
Nina Usatenko' (iD, Sergii Verbytskyi² (i) \\ Cite this article as: Usatenko, N., \& Verbytskyi, S. (2021). Upgrading air distribution system in the thermal units for fish and meat products aiming \\ at improving efficiency of heat-exchange processes. Aquatic Sciences and Engineering, 36(3), 146-151.
}

ORCID IDs of the author: N.U. 0000-0002-0339-5189; S.V. $0000-0002-4211-3789$

'Pereiaslav-Khmelnutskyi Hryhoriy Skovoroda State Pedagogical University, Kyiv, Ukraine

Institute of Food Resources of National Academy of Agrarian Sciences of Ukraine, Kyiv, Ukraine

Submitted:

28.11.2020

Revision Requested: 01.03.2021

Last Revision Received: 07.03.2021

Accepted:

08.03.2021

Online Published:

13.04.2021

Correspondence:

Sergii Verbytskyi

E-mail:

tk140@hotmail.com

CCopyright 2021 The Author(s)

Available online at

https://dergipark.org.tr/ase

\begin{abstract}
The issue of the equivalence of the physical parameters of the working medium in the heat-treatment zone of fish and meat products is solved by organizing uniform high-speed fields of the working medium in the working area, which is ensured by the corresponding design. The aerodynamic characteristics of a double-sided centrifugal blower fan with a vertical arrangement of the drive shaft and a spiral scroll with two outlet openings, the outlines of which were carried out according to the design square rule, provided that the opening and width of each outlet was equal to the half-opening and half-width of the outlet of the spiral case of the industrial prototype, were investigated. When testing the aerodynamic characteristics of a double-sided blower, the identities of the full and dynamic air pressure developed by the fan at all points of the measured cross-section of each of the two oppositely directed outlet pipes are established to be identical, which indicates the equalization of air flows. In this case, the dimensionless ratio of the cross-sectional areas of the equistatic pressure duct to the initial pressure is 0.20 , and the cross-sectional area for the air passage of the heat exchanger, conditionally being the perforated base of the duct, was $0.0978 \mathrm{~m}^{2}$. The test results confirmed the reliability of analytical calculations and the feasibility of using these fans, which reduces energy consumption, a specific quantity of metal, and the cost of equipment in general.
\end{abstract}

Keywords: Fish and meat products, Aerodynamic characteristics, Double-sided blower fan, Equistatic pressure duct, Convection, Thermal unit

\section{INTRODUCTION}

Despite the widespread use of equipment for the food industry at numerous enterprises of this profile, the issue of updating the machinery and equipment fleet and the technical improvement of such equipment has been rather outside the field of view of scientists and specialists for years, negatively affecting the development of the Ukrainian industry in the above-mentioned industrial sectors. Among the primary issues to be solved is the energy efficiency of said equipment (Kovalenko et al., 2020). The heat treatment process is among the principal operations of fish and meat products' manufacturing technology, said process being carried out by the method of convective heat supply to the product in modular type rooms (thermal units) (Ivashov, 2007; Belova et al., 2013, Urazov, 2015), thermally insulated from the external environment. However, literature sources on the processes that occur during this processing are rather rare and fragmented. In particular, the food safety issues of the process are disclosed in (Usatenko et al., 2019a), the issues of rationalizing the working area of thermal units are considered in (Pöhlmann et al., 2013), the influence of the working elements of the thermal unit on the temperature field inside it is described in (Pöhlmann et al., 2012), and the features of the effect of the design of the thermal unit on the nature of the ongoing heat exchange processes are described in 
(Ledesma et al., 2016). The problems of the effective supply of the working medium to the working zone of a thermal unit, as well as the effective distribution of the specified medium in the space filled with the product being processed, are given in (Alakali et al., 2017). The structural elements of a thermal unit, which provide the dynamic process of formation of the smoke-air mixture during the smoking of food products of animal origin, are described in (Adeyeye, 2019). In particular, a properly selected fan plays an important role in ensuring uniform heat transfer and mass transfer in the working volume of the thermal unit during the heat treatment of the above-mentioned products (Adepoju et al., 2018). The importance of continuous effective temperature regulation and of maintaining a certain relative humidity of the working environment during the heat treatment is described in (Škaljac et al., 2018).

An obligatory element of the regulation of the technological process in the working area of a thermal unit is to check the uniformity of the air supply and its distribution, as well as temperature. The check should be carried out both at normal ambient and at elevated temperatures. When the air heats up, its volume increases, and thus, the circulation fan supplies the same amount of air (by volume) into the chamber but the amount is less by weight. Controlling the flow of hot air is much more complicated than controlling the flow of heavier cold air. For this reason, the balancing of air flows inside the chamber should be carried out both at a colder ambient temperature, as well as at an elevated temperature. Both temperature and air velocity are determined at various points inside the chamber. In case of significant deviations, it is necessary to adjust the distribution system of air flows in the working volume (Waters, 2010) in a proper way.

As a rule, one of the technological processes carried out in industrial universal thermal units is the smoking of fish and meat products, which involves processing the product with a smokeair working environment. The nature of this process depends on the composition of the smoke-air mixture, its temperature, humidity, and density, as well as on the speed and technical implementation of its supply, the distribution efficiency in the working volume of the chamber, and the design of the units supplying the smoke-air mixture into the chamber (Kubiak et al., 2014; Kubiak \& Jakubovski, 2013; Sikorski \& Kołakowski, 2010). Factors that determine the achievement of the required sensorial and chemical properties of the smoked product are such parameters as temperature, density, and the intensity and rate of mixing smoke and air in the working area of the chamber during the entire process (Kubiak \& Jakubowski, 2010a; Kubiak \& Jakubowski, 2010b). The required regulation of the production cycle, in particular smoke flows - air mixture, when processing fish and meat in a heat chamber is facilitated by innovative microprocessor technology (Kubiak et al., 2014).

As can be seen from the above, the most important condition of the heat treatment process carried out in thermal units is the equivalence of the physical and chemical parameters of the working medium flowing around each product unit taken from the number of product units processed simultaneously (Kosoy et al., 2018; Bondarenko, 2013), which is possible with the uniformity of the velocity fields of the working medium in the heat treatment zone.
The solution of this problem, as a rule, narrows down to the development of an effective aerodynamic system composed of such basic elements as: a fan, air ducts, heat exchangers, and a control system, with the help of which the necessary physical and chemical parameters of the working medium recirculated in a turbulent mode within the volume of the heat chamber with the product are being maintained (Study, 1994). At the same time, along with the fundamental requirement for the process - ensuring high quality of finished fish and meat products, the economical component related to reducing energy consumption, metal consumption, and, accordingly, costs shall be considered.

Among the most important issues when solving the problem is the fan, forcing air to move in the confined space of the working chamber; the aerodynamic characteristics of the said fan substantiate the efficiency of the heat applied to the fish and meat products by means of convection. The fan motor, when overcoming the resistance of the elements of the aerodynamic system, consumes a significant amount of electricity in the operating mode. Therefore, the selection of a recirculation fan is usually carried out after conducting comprehensive studies of the effectiveness of convective heat transfer processes, allowing for the structural and functional features of all elements of the aerodynamic network. The design features of the network elements, their interaction and orientation relative to each other, are the basics to determine the preparation of the working medium flows and its uniform dispersal throughout the chamber filled with the product, in accordance with the given technological parameters.

The formation of the working medium flows identical in physical parameters in the working volume of the chamber begins directly after the recirculation fan, when the continuous working medium flowing from its discharge pipe should be divided into two, both being identical but opposite to the peripheral sides of the chamber. Further, using the duct system, the flow geometry is transformed to obtain free or limited flooded jets at the entrance to the heat treatment zone of the product, the said jets being equivalent in aerodynamic characteristics.

When procuring thermal units, taking into account the significant aerodynamic drag of the system, industrial centrifugal high-pressure fans are usually used, both with a case and, less often, without one. The number of the first ones, as a rule, is doubled on each module, using an equal number of left and right fans and organizing, at the same time, their work in a cyclic mode (Kubiak et al., 2014; Smyshlyaev, 2004). This allows the avoidance of the operation of dividing the flow into two oppositely directed flows. As practice shows, this negatively affects the longevity of fan motors - due to the presence of periodically repeating starting loads.

The disadvantage of the fans without cases consists in their low-pressure aerodynamic characteristics, and the fact they provide neither the efficiency of heat removal from heat exchangers nor the necessary kinematic parameters of the working medium in the working volume of the chamber (Study, 1994). 


\section{STUDY OBJECTS AND METHODS}

This work aims at the development of a double-sided blower fan and equistatic pressure ducts to improve the air distribution system in the chambers intended for the heat treatment of fish and meat products.

The objects of study are the aerodynamic characteristics of a centrifugal double-sided blower fan and the geometric characteristics of air ducts of equal pressure as the main elements. determining the nature of the movement of air within the working volume of thermal units.

Taking into account sufficiently significant hydraulic resistances of the elements of the aerodynamic system (calculated data) and technological assumptions regarding the velocity of the working medium near the product ( $2 \mathrm{~m} / \mathrm{s}$ ), the industrial centrifugal fan VTs 14-46-4 was adopted as a prototype when developing a double-sided blower, equipped with an electric motor of the AIR$100 \mathrm{~L} 6 \mathrm{~T} 1$ series with a power of $\mathrm{N}=2.2 \mathrm{~kW}$ and $\mathrm{n}=1000 \mathrm{rpm}$. The rated capacity of the fan is $V \approx 6000 \mathrm{~m}^{3} / \mathrm{h}$, pressure $\mathrm{P} \approx 670 \mathrm{~Pa}$.

The new fan unit was fitted up based on the use of the impeller and electric motor of the above-mentioned prototype fan. The unit casing was a double-sided spiral scroll specially designed for this case (Figure 1), the outlines of which were carried out according to the rule of design square [22]. Moreover, the opening and width of each of the two outlets was equal to the half-opening and half-width of the outlet opening of the VTs 14-46-4 fan spiral casing, and the total size of the measured cross-sectional areas of the outlet openings was equal to the measured cross-sectional area of the prototype outlet.

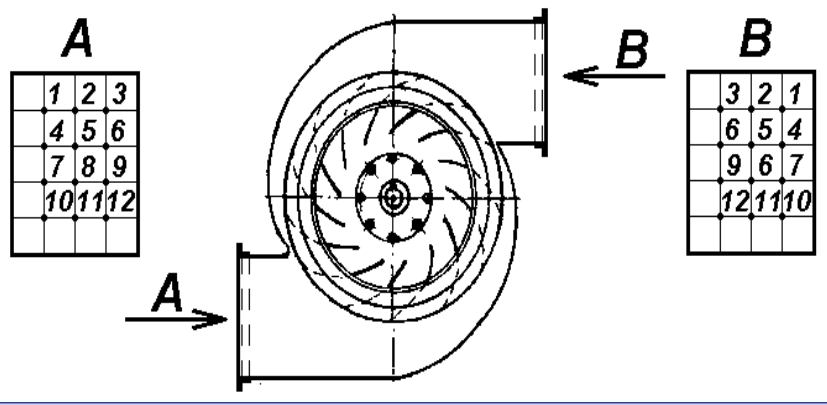

Figure 1. Diagram of a double-sided fan blower with the location of pressure measuring points in measured sections of outlet pipes: $A$ - left; $B$ - right.

When developing the design of the new fan blower, a vertical arrangement of the elongated drive shaft of the electric motor was provided in a special way, which allowed the latter to be moved outside the hot zone of the chamber (the temperature of the working medium is up to $100^{\circ} \mathrm{C}$ ), thereby avoiding the phenomenon of systematic overheating of bearings, significantly reducing their service life.

To conduct in situ tests of the objects of study, on the basis of analytical calculations - caloric and hydraulic resistances with a si- multaneous outline study of the elements of the aerodynamic system (Solomakhova, 1975; Idelchik, 2013; Grimitlin, 1994), an experimental module of the heat treatment chamber was made, the diagram of which is shown in Figure 2.

The module was arranged according to the principle of symmetry with the axis of symmetry of the module coinciding with the central axis of the cylindrical suction pipe of the recirculation fan 1. In this case, the design of the right side of the module relative to the suction pipe of the fan was a mirror image of the structure of the left side. The outlet (pressure) pipes of the fan with welded cylindrical nipples 2 (Figure 2) are inextricably connected by means of connecting rotary air ducts 3 with equistatic pressure ducts 4 and bimetallic heat exchangers 5 .

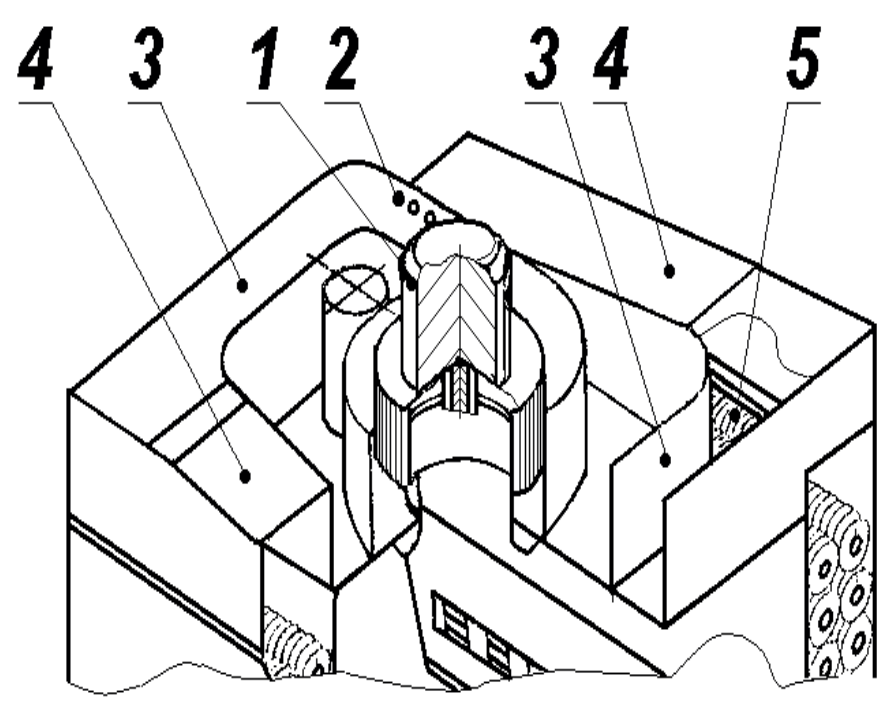

Figure 2. Scheme of the experimental setup module: 1 centrifugal fan for double-sided blowing; 2 cylindrical nipples with plugs; 3 - connecting turnable duct; 4 - equal pressure duct; 5 - finned bimetallic heat exchanger.

Each of the aforementioned elements of the aerodynamic network functionally complemented each other to obtain the uniform dispersion of the flow of the working medium along the sides of the module and, further, its uniform supply to the heat treatment zone of the product. So finned bimetallic heat exchangers, in addition to their direct function of heating the air, also served as the perforated base of the equistatic pressure ducts 4, or, in other words, as the distribution grid for the air flows flowing from these ducts. The total calculated aerodynamic drag of the system elements was approximately 550 Pa (Idelchik, 2013; Pozin et al., 1996), which corresponded to the certified value of the pressure developed by the analogue fan.

The uniformity of air flow distribution along the length of each equal pressure duct 4 (Figure 2) was established by changing the angle of inclination of its movable upper generatrix 2 (Figure 3 ) to the base. 
The base of the air duct was a heat exchanger with a corridor arrangement of finned tubes 3 (Figure 3 ) and the cross-sectional area for air passage $-0.0978 \mathrm{~m}^{2}$. The design of the heat exchange surface was created by casting molten aluminum onto a hot rolled steel pipe. With the height of the aluminum fin $h=d_{0}$ and its efficiency $E$ $=0.77$, the heat transfer coefficient, taking into account the deposition of smoke components on a bimetallic surface with a thickness of about $1 \mathrm{~mm}$, amounted to $\mathrm{k}=42.6 \mathrm{~W} / \mathrm{m}^{2} \mathrm{~K}$, and the maximum aerodynamic resistance - $144 \mathrm{~Pa}$. The high thermal characteristics of the heat exchanger significantly reduced its metal consumption, and the insignificant aerodynamic drag contributed to a decrease in the power of the recirculation fan electric motor. Equal pressure of air distributed along the length of air duct 1 (Figure 3), in the case of changing the type of heat exchange surface, is ensured by using a perforated bottom with the cross-section for air passage equal to the free section of the heat exchanger.

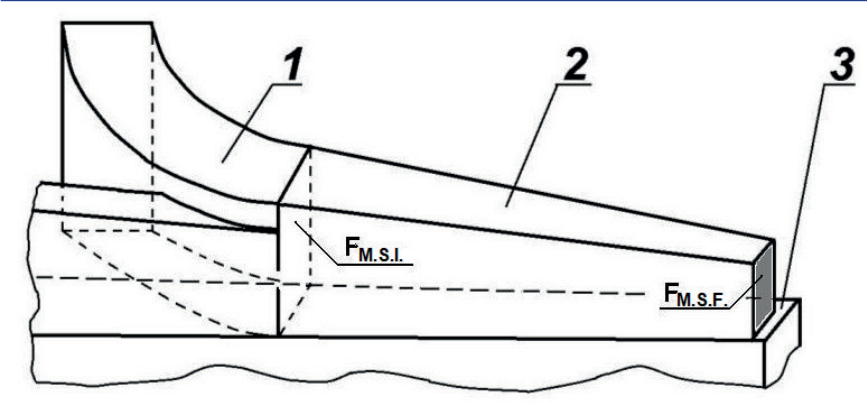

Figure 3. Diagram of the blowing ducts of the aerodynamic network: 1 - connecting turnable duct; 2 - the movable upper duct of the equal pressure duct; 3 heat exchanger

To determine the rational geometrical parameters of the equal pressure duct, a generalizing dimensionless parameter was used, the value of which was calculated as the ratio of the cross-sectional area of the equal pressure duct - the final (variable) area to the initial (unchanged and commensurate with the geometric parameters of the corresponding output section of the fan discharge pipe):

$$
\bar{F}=\frac{F_{M . S . F}}{F_{M . S . I .}}
$$

where: $F_{\text {M.S.F. }}$ - the cross-sectional area of the duct at its end; $F_{\text {M.S.I. }}$ - the cross-sectional area of the duct at its beginning.

The rationality of the layout of the centrifugal double-sided fan of the applied electric motor was carried out in the operating mode by measuring the current consumption using the K-50 measuring set, the measurement limit was 1.0-600.0 A, accuracy class $\pm 0.5 \mathrm{~A}$.

The measurement of the velocity of the air flow in the measured sections of the blow pipes of the fan and blow ducts was investigated using: hand induction anemometer ARI-49, measurement range $1.0 \div 30.0 \mathrm{~m} / \mathrm{s}$, accuracy $\pm 0.5 \mathrm{~m} / \mathrm{s}$; cup anemometer MS13 , measurement range $1.0 \div 20.0 \mathrm{~m} / \mathrm{s}$, accuracy $\pm(0.1+0.05)$ $\mathrm{m} / \mathrm{s}$ and electrothermal anemometer - TA-LIOT, measurement range $0.0 \div 5.0 \mathrm{~m} / \mathrm{s}$, accuracy $\pm(0.1+0.05) \mathrm{m} / \mathrm{s}$. The pressure was measured using a combined pneumometric fitting with a cylindrical head (correction coefficient of the bevel of the fitting during calibration of $k_{n}=0.95 \pm 1.0$ ) and the differential alcohol micromanometer MMN-240 (5) -1.0, accuracy class 1.0.

The proportionality of the aerodynamic characteristics of the air flows generated in the double-sided blower was determined on the basis of a comprehensive comparative study of the total and dynamic pressure in the equal-sized and equal-distant from the impeller measured sections of and pressure ducts opposite the fan axis at the same temperature and humidity and avoiding leaks and suction from the outside. To fix the receiving part of the combined pressure measuring transducer perpendicularly to the flows of air leaving the pipes, cylindrical fittings with plugs 2 (Fig. 2) were welded at characteristic numbered measuring cross-section points (Figure $1-A$ and $B$ ).

The average air pressure at the characteristic points of the measured sections was calculated by the formula:

$$
P_{\text {iavg. }}=\frac{\left(\sqrt{P_{i 1}}+\sqrt{P_{i 2}}+\sqrt{P_{i 3}}+\ldots+\sqrt{P_{i n}}\right)^{2}}{n}
$$

where: $\mathrm{n}$ is the number of measurements; $\mathrm{i}$ - type of measured pressure (static, dynamic, full) at the corresponding characteristic point.

The average air flow rate over the measured section of each pressure pipe of the fan was determined based on the average value of the dynamic pressure in the corresponding section:

$$
W_{\text {avg. }}=\sqrt{\frac{2 P_{\text {davg }}}{\rho}}
$$

where: $\rho$ is the air density, $\mathrm{kg} / \mathrm{m}^{2}$.

The volume of air flowing over the measured cross-section of each pressure pipe of the fan was calculated by the formula:

$$
V=F \cdot W_{a v g}, m^{3} / s
$$

where: $F$ is the measured cross-sectional area equal to $0.0375 \mathrm{~m}^{2}$ for this particular case.

\section{RESULTS AND DISCUSSION}

The results of field and analytical studies of the aerodynamic characteristics of a centrifugal double-sided fan are shown in Table 1.

An analysis of the results of analytical and full-scale studies of the aerodynamic characteristics of the developed double-sided blower (Table 1) indicates a fairly complete identity of the significant parameters characterizing the alignment of air flows and a decrease in the effect of turbulence in the output measured sections of each of the two oppositely directed blow pipes. The discrepancy between the pressure indicators (full and dynamic) in the left and right outlet openings of the blow pipes was within the accuracy limits of measuring instruments and can be explained by an insufficiently perfect impeller balancing quality. 
Table 1. The results of analytical and full-scale studies of aerodynamic characteristics of a double-sided centrifugal fan.

\begin{tabular}{|c|c|c|c|c|c|c|c|c|c|c|c|c|c|}
\hline $\begin{array}{l}\text { Aerodynamic } \\
\text { characteristics of fan }\end{array}$ & \multicolumn{12}{|c|}{ Measurement points numbers in measured sections } & $\begin{array}{c}\text { Average } \\
\text { value }\end{array}$ \\
\hline \multicolumn{14}{|c|}{ Pressure in measured section of the left blow pipe, $\mathrm{Pa}$} \\
\hline dynamic, $\mathrm{P}_{d}$ & 319 & 292 & 319 & 319 & 292 & 266 & 319 & 292 & 266 & 292 & 292 & 266 & 301.0 \\
\hline \multicolumn{14}{|c|}{ Pressure in measured section of the right blow pipe, $\mathrm{Pa}$} \\
\hline \multicolumn{13}{|c|}{ Average air flow velocity in measured section of the left blow pipe, $\mathrm{m} / \mathrm{s}$} & 22.40 \\
\hline \multicolumn{13}{|c|}{ Average air flow velocity in measured section of the right blow pipe, $\mathrm{m} / \mathrm{s}$} & 22.38 \\
\hline \multicolumn{13}{|c|}{ Calculated value of air volume flowing in measured section of the left blow pipe, $\mathrm{m}^{3} / \mathrm{s}$} & 0.842 \\
\hline \multicolumn{13}{|c|}{ Calculated value of air volume flowing in measured section of the right blow pipe, $\mathrm{m}^{3} / \mathrm{s}$} & 0.841 \\
\hline \multicolumn{13}{|c|}{ Average calculated performance of the double-sided blowing fan, $\mathrm{m}^{3} / \mathrm{s}$} & 1.68 \\
\hline
\end{tabular}

The results of measuring the current consumed by the electric motor in the operating mode of the current showed that its actual value corresponded to the nominal value - 5.4 A, and the fan performance was $1.68 \mathrm{~m}^{3} / \mathrm{s}\left(6059.0 \mathrm{~m}^{3} / \mathrm{h}\right)$, which is comparable with the certified technical characteristics of the centrifugal industrial fan VTs 14-46-4, taken as a prototype.

The averaged data on the study of the physical characteristics and uniformity of the distribution of air flows along the length of each of the two equal pressure ducts 4 (Figure 1), depending on the value of the generalizing parameter, are shown in Table 2. The measurements were carried out in measured sections at the outlet of the heat exchangers 5 (after straightening the flows) every $0.1 \mathrm{~m}$ with the length of each duct and, accordingly, the heat exchanger equal to $1.0 \mathrm{~m}$

Based on an analysis of the results of studying air flow velocities along the length of air ducts for different values of the generalizing parameter, it was found that the best uniformity of air distribution and, as a result, more efficient heat removal from the heat exchanger is achieved with the value of the generalizing parameter:

$$
F=\frac{F_{\text {M.S.F. }}}{F_{\text {M.S.I. }}}=0.20
$$

The data obtained served as the basis for halving the number of fans when completing thermal units: replacing the two left and right VTs 14-46-4 twin industrial centrifugal fans, alternately switched on during operation, with one double-sided fan. At the same time, to improve the uniformity of the dispersion of air flows along the sides of the chamber, it was envisaged to tie the fans with equistatic pressure ducts, structurally made in accordance with the calculated value of the generalizing dimensionless parameter equal to 0.20 and the use of finned heat exchangers that functionally perform the role of the perforated bottom of the duct, and heat source for heating the flowing air.

The successful implementation of these technical solutions took place when creating the designs of universal heat chambers and cooling chambers for food products that are produced by the machine-building company "VI-VA LTD" (Ukraine) and resulted in a rather significant reduction in metal consumption and equipment and operating costs in general (Usatenko et al., 2019b).

\section{CONCLUSION}

Thus, oppositely directed compact flows of the working medium with the same aerodynamic characteristics were obtained using the developed double-sided fan with a vertical drive shaft and a spiral scroll with two outlet openings, the outlines of which were made according to the design square rule, provided that the opening and width of each outlet were equal to the half-opening

Table 2. Averaged data of the study of physical characteristics and uniformity of distribution of air flows formed in equistatic pressure ducts depending on the value of the generalizing parameter.

\begin{tabular}{|c|c|c|c|c|}
\hline $\begin{array}{l}\text { Generalizing } \\
\text { parameter } \\
\bar{F}=\frac{F_{M . S . F .}}{F_{M . S . I .}}\end{array}$ & $\begin{array}{l}\text { The volume of air } \\
\text { pumped by the fan } \\
\text { over a measured } \\
\text { cross-sectional area } \\
F_{\text {m.s.i. }} \mathrm{m}^{3} / \mathrm{s}\end{array}$ & $\begin{array}{l}\text { The average air } \\
\text { velocity in a mea- } \\
\text { sured cross-sectional } \\
\text { area } F_{\text {m.s.i., }} \mathrm{m} / \mathrm{s}\end{array}$ & $\begin{array}{l}\text { The average air velocity } \\
\text { in a measured section at } \\
\text { the outlet of the finned } \\
\text { heat exchanger, } \mathrm{m} / \mathrm{s}\end{array}$ & $\begin{array}{l}\text { The uniformity of the } \\
\text { distribution of air flows } \\
\text { along the length of the } \\
\text { duct of equistatic } \\
\text { pressure, \% }\end{array}$ \\
\hline 0.15 & $0.84 \pm 0,01$ & $21.0 \pm 0,1$ & $8.6 \pm 0,1$ & 2.3 \\
\hline 0.20 & $0.84 \pm 0,01$ & $21.0 \pm 0,1$ & $8.6 \pm 0,1$ & 1.0 \\
\hline
\end{tabular}


and half-width of the outlet of the spiral casing of an industrial centrifugal prototype fan. This allowed to halve the number of recirculation fans equipped with each module of the thermal unit.

The uniform distribution of the working medium flows along the side walls of the module, before it enters the product heat treatment zone, was achieved due to the design features and the relative positioning of the elements of the aerodynamic system equistatic pressure ducts and finned bimetallic heat exchangers.

It was established that the configuration of the heat chamber with the created elements of the aerodynamic system contributes to the improvement of the kinematic component of the process of bringing heat to fish and meat products by forced convection while reducing the metal consumption, energy consumption, and the cost of the equipment as a whole.

Conflict of interest: The authors declare that they have no conflict of interest.

\section{Ethics committee approval: -}

\section{Funding: -}

\section{REFERENCES}

Adepoju, M. A., Omitoyin, B. O., Ajani, E. K., \& Asha, K. (2018). Effect of Smoking Time and Temperature on the Proximate Composition and Quality of Milkfish Steaks. Journal of aquatic food product technology, 27(3), 369-378. [CrossRef]

Adeyeye, S. A. O. (2019). Smoking of fish: a critical review. Journal of Culinary Science \& Technology, 17(6), 559-575. [CrossRef]

Alakali, J. S., Adekoyeni, O. O., Alaka, I. C., Faasema, J., \& Torvor, T. (2017). Fabrication and Performance Evaluation of A Hybrid Fish Smoking Kiln. Journal of Food Processing and Preservation, 41(3), e12935. [CrossRef]

Belova, M. A., Aleksandrova, G. A., Poruchikov, D. V., \& Novikova, G. V. (2013). Processing equipment for heat treatment of agricultural raw materials. Herald of Chuvashia State Pedagogical University named after I. Ya. Yakovlev, 2(78), 12-15.

Bondarenko, N. V. (2013). Research of heat treatment of boiled sausages in advanced thermal chambers. Food Science and Technology, 2(23), 92-93.

Erdoğdu, F. (2005). Mathematical approaches for use of analytical solutions in experimental determination of heat and mass transfer parameters. Food Eng., 68(2), 233-238. [CrossRef]

Grimitlin, M. I. (1994). Indoor air distribution. St. Petersburg: NPO Ehkoyurus-Vento, 316.

Idelchik, I. E. (2013). Reference book on fluid resistance. Moscow: Ripol Classic.

Ivashov, V. I. (2007). Technological equipment of the enterprises of meat industry, equipment for meat processing, part 2, 310. St. Petersburg: GIORD; ISBN 5-93879-023-2.

Kosoy, V. D., Ryzhov, S. A. \& Dorokhov, V. P. (2018). Improving the process of sausages production (theoretical bases, processes, equipment, formulations and quality control). Moscow: DeLi, 682; ISBN: 978-56041606-1-9.

Kovalenko, O., Verbytskyi, S., Yashchenko, L., \& Lysenko, H. (2020). Peculiarities of technical means of meat processing industry in
Ukraine. The Scientific Journal of Cahul State University "Bogdan Petriceicu Hasdeu" Economic and Engineering Studies, 1(7), 66-72.

Kubiak, M. S., \& Jakubowski, M., (2010a). Model symulacyjny warunków przepływu w komorze wędzarniczej. Postępy Techniki Przetwórstwa Spożywczego, 1, 55-57.

Kubiak, M. S., Jakubowski, M., (2010b). Trójwymiarowa analiza symulacyjna CFD rozkładu pola prędkości przepływu mieszaniny dwufazowej w komorze wędzarniczej. Nauka Przyroda Technologie, 4, 5-66.

Kubiak, M. S.; \& Jakubowski, M. (2013). CFD simulations as a supporting tool of process and construction optimization in food industry production practice: the case study of a single truck smoking chamber. Italian Journal of Food Science, 25(3), 251-254.

Kubiak, M. S., Jakubowski, M., \& Dolata, W. (2014). Computational Fluid Dynamics (CFD) innowacyjne narzędzie do symulowania procesu wędzenia oraz modelowania elementów konstrukcji komory wędzarniczo-parzelniczej. Agricultural Engineering, 18.

Ledesma, E., Laca, A., Rendueles, M., \& Díaz, M. (2016). Texture, colour and optical characteristics of a meat product depending on smoking time and casing type. LWT - Food Science and Technology, 65, 164172. [CrossRef]

Pozin, G. M., Belyaev, K. B., Nikulin, D. A., \& Strelets, M. Kh. (1996). Issues of improving methods of calculation of air exchange and air distribution basing on approximate and precise mathematic models. Materials of 5th Congress of AVOK, 165-170.

Pöhlmann, M., Hitzel, A., Schwägele, F., Speer, K., \& Jira, W. (2012). Contents of polycyclic aromatic hydrocarbons (PAH) and phenolic substances in Frankfurter-type sausages depending on smoking conditions using glow smoke. Meat Science, 90(1). [CrossRef]

Pöhlmann, M., Hitzel, A., Schwägele, F., Speer, K., \& Jira, W. (2013). Polycyclic aromatic hydrocarbons (PAH) and phenolic substances in smoked Frankfurtertype sausages depending on type of casing and fat content. Food Control, 31, 136-144. [CrossRef]

Sikorski, Z. E.; \& Kołakowski, E. (2010). Smoking, in Handbook of Meat Processing (Ed Toldrá F.), Chapter 12. Wiley-Blackwell, Oxford, UK, 231-245; ISBN 978-0-9138-2182-5.

Škaljac, S., Jokanović, M., Tomović, V., Ivić, M., Tasić, T., Ikonić, P., ... \& Petrović, L. (2018). Influence of smoking in traditional and industrial conditions on colour and content of polycyclic aromatic hydrocarbons in dry fermented sausage "Petrovská klobása". LWT - Food Science and Technology, 87, 158-162. [CrossRef]

Smyshlyaev, P. V. (2004). Optimal control system of thermal chambers. PhD Thesis, 139.

Solomakhova, G. S. (1975). Centrifugal blower fans. Moscow: Machinebuilding, 415 .

Study of heat-and-mass exchange processes in the thermal processing of meat products to optimize technology and design of equipment. (1994). Scientific Report No 3.91, Kyiv: TIMM UAAN, 102.

Usatenko, N., Kalashnik, M., Dobroskok, S., \& Verbitskyi, S. (2019a). Prerequisites to improve the safety of smoked foodstuffs. Scientific Horizons, 6(79), 29-35. [CrossRef]

Usatenko, N. F., Shchesyuk, O. V., Verbytskyi, S. B., Kalashnik, M. G., Dobroskok, S. S. (2019b) Efficiency improvement of heat and mass exchange processes in the production of dry sausages. Food Industry: Science and Technologies, 12(4), 20-27.

Urazov, D. Yu. (2015). Scientific support of the process of thermal and humid processing of sausage products. PhD Thesis, 186.

Waters, E. (2010). Appendix A: Objectives and critical elements of thermal processing of ready-to-eat meat products. Processing of Ready-to-eat Meat Products; ISBN 978-0-8138-0148-3. 